\title{
THE EFFICIENCY OF OPTICAL MICROSTRUCTURES FORMED ON MOLYBDENUM FILMS
}

\author{
S.D. Poletayev ${ }^{1,2}$, S.G. Volotovsky ${ }^{1,2}$ \\ ${ }^{1}$ Image Processing Systems Institute - Branch of the Federal Scientific Research Centre "Crys- \\ tallography and Photonics" of Russian Academy of Sciences, Samara, Russia \\ ${ }^{2}$ Samara National Research University, Samara, Russia
}

\begin{abstract}
We have considered influence of technological errors of formation of the amplitude optical lattices made by method of a laser ablyation of thin films of molybdenum on distribution of diffraction orders in a distant zone of diffraction. For this purpose we have digitized a profile of a site of the created diffraction structure with the subsequent transformation to amplitude or phase functions of a transmission.
\end{abstract}

Keywords: diffractive microrelief, metallic mask, laser ablation, thermochemical recording, film molybdenum, reactive ion etching.

Citation: Poletaev SD, Volotovsky SG. The efficiency of optical microstructures formed on molybdenum films. CEUR Workshop Proceedings, 2016; 1638: 882-887. DOI: 10.18287/1613-0073-2016-1638-882-887

\section{Introduction}

Currently the ablation of metal films is widely used by laser radiation in such areas as semiconductor production, photo-electric devices, diffraction lattices and other hightechnology appendices [1-9]. In this field researches is actual the task of forming of the amplitude diffraction optical elements (DOE), and also the masking layers applied to transfer of a microrelief in a substrate is actual. In this respect is perspective thin films of molybdenum [6] as molybdenum has the following features are perspective: - low temperatures of oxidation of metal, and oxide sublimation;

- high ratio of heat diffusivities metal/oxide.

In works [10-12] the possibility of forming of optical microstructures by a laser ablation of thin films of molybdenum is shown. The effect of triple reducing the size of a zone of an ablation has been found (in comparison with diameter of a focal spot). However edges of tracks turned out uneven, around tracks heat-affected zone (HAZ) caused by metal oxidation was created. 
The purpose of this work consists in identification of influence of technological errors of production of lattices on efficiency of their work.

Modeling of a spatial range of focusing in a distant zone has been for this purpose carried out.

\section{Methods and materials}

Microstructures were formed at station of the laser record CLWS-200 [13-14] in the following sequence of technological operations:

- a dusting of a thin film of molybdenum on a substrate;

- formation of a test lattice by a local ablyation of a film under the influence of laser radiation.

Optically smooth substrates from glass and fused quartz the size $50 \times 50$ of $\mathrm{mm}, 3 \mathrm{~mm}$ thick formed the basis. Film of molybdenum with a thickness of $17 \mathrm{~nm}$ were deposited by magnetron sputtering method on the instruments «Caroline D-12A» (Russia, Zelenograd) under the following conditions: a magnetron power - $700 \mathrm{~W}$, substrate temperature $-200^{\circ} \mathrm{C}$, the argon pressure $-0,2 \mathrm{~Pa}$. Deposition time was $2 \mathrm{~min}$.

Laser recording was carried out under the following conditions: the working length of the laser wavelength - $488 \mathrm{~nm}$; the maximum power delivered to the recording head $100 \mathrm{~mW}$; record structure - concentric rings with step $3 \mu \mathrm{m}$ and an outer radius of 3 $\mathrm{mm}$; the amount of power to each ring is decreased from $100 \%$ at the point of largest radius to the center 0 in increments of $0.5 \%$. Sample rotation speed $-10 \mathrm{~s}^{-1}$. These process parameters correspond to the maximum laser density of power $\mathrm{E}_{\max }=20$ $\mathrm{MW} / \mathrm{cm}^{2}$. The impact of laser radiation led to local ablation of the molybdenum film.

\section{Analysis of the results}

The fragment of the analyzed lattice is given in fig. 1 [10]. The width of the tracks is in the range of $250-400 \mathrm{~nm}$.

The structure shown in fig. 1 through binarization can be converted to a binary diffraction grating (Fig. 2b).

The resulting structure is an amplitude grating with different sized areas. In this case the resulting amplitude is a lattice, but can easily be converted into a phase diffraction grating. Consider the work of the resulting structure in both cases.

For clarity, in fig. 3 shows the profilogram a plot of the derived structure (fig. 3a), taken in a direction perpendicular to the recording tracks, by using a profilometer KLA-Tencor P16+. The profile is the same binary grating shown in Fig. $3 \mathrm{~b}$.

To calculate the intensity distribution in the far zone of diffraction of a plane light wave in the considered two-dimensional structure used fast algorithms of direct calculation of the Fourier transform [15-17].

Calculation based on numerical integration, in contrast to the algorithms of the fast Fourier transform, allows to correctly evaluate the physical characteristics of the generated fields. This is especially important in the analysis of the dispersive properties of diffraction gratings [18, 19]. 


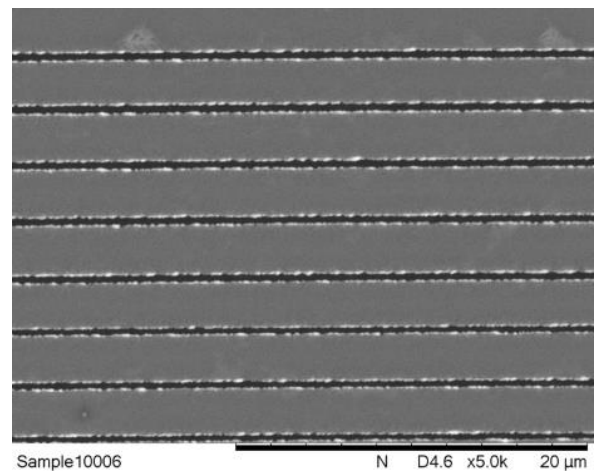

Fig. 1. Image of the lattice analysed
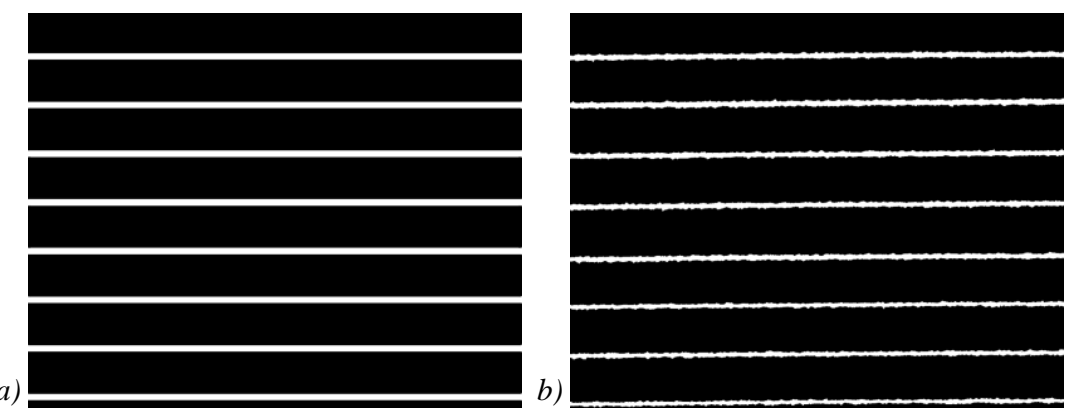

Fig. 2. Transformed an ideal (a) and (b) lattice (negative image)
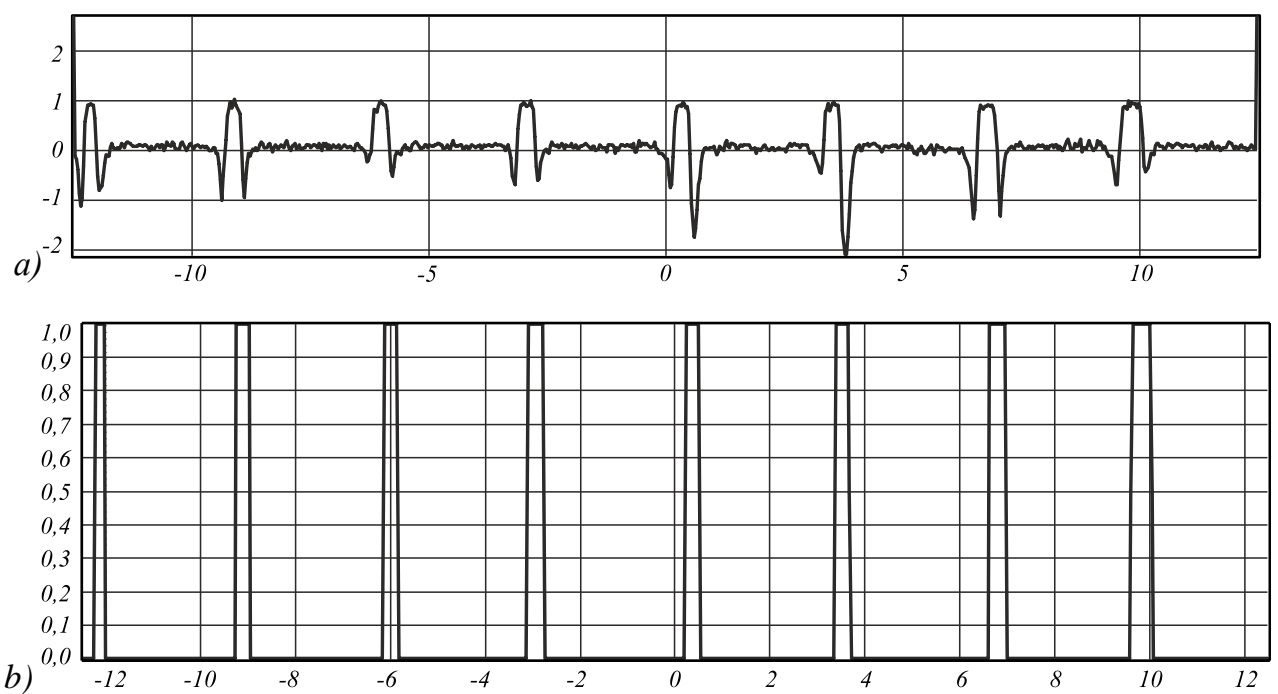

Fig. 3. The profiles plot (a) real and (b) given to the binary appearance of the diffraction structure 
In fig. 4a shows the intensity distribution in order, in fig. $4 \mathrm{~b}$ is the same distribution together with the intensity distribution of an ideal amplitude grating (fig. 2a) with the same period and width of the tracks.

The standard deviation of the two graphs in fig. $4 \mathrm{~b}$ is 0.26 , given the nature of the distribution, is not a big mistake.

Was also simulated diffraction by a phase grating of this type. This digitized distribution shown in fig. 1, was transformed into the phase transmission function, the profile of which is shown in fig. 5 .

In fig. 6a shows the distribution of intensity in the far zone of diffraction obtained after using the Fourier transform. In Fig. $6 \mathrm{~b}$ shows the same distribution compared to the distribution of ideal phase grating with the same period and width of the tracks.

Mean-square deviation of the two graphs in fig. $6 \mathrm{~b}$ is 0.21 , which, given the nature of the distribution, is also not a big mistake, because in this case more important than an exact match of the positions of the maximum.
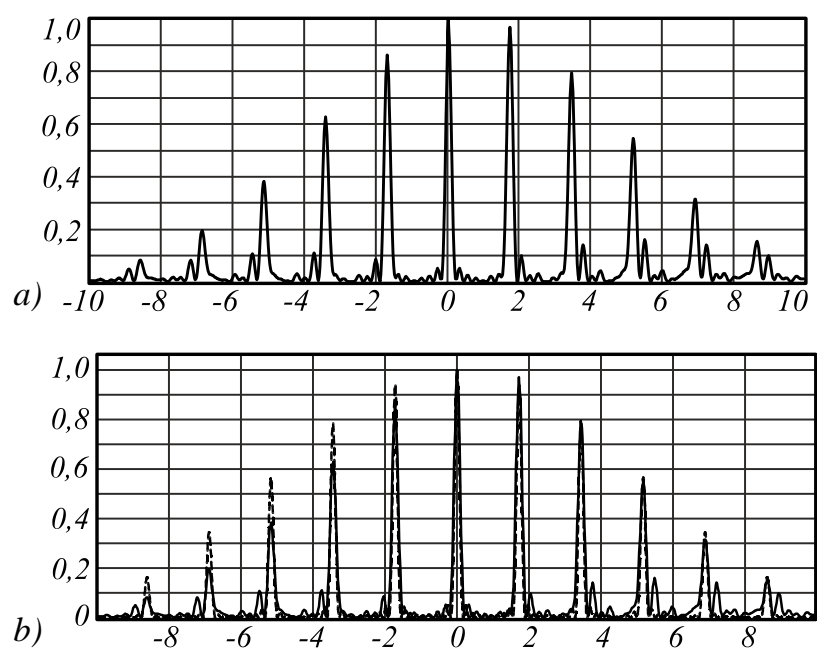

Fig. 4. The intensity distribution orders in the far zone of diffraction from the amplitude structure, shown in fig. 3 (a), the same distribution of intensity on the order in the far zone of diffraction from the amplitude structure, shown in fig. $2 \mathrm{~b}$ ) compared to the distribution from a perfect lattice (dashed line) (b)

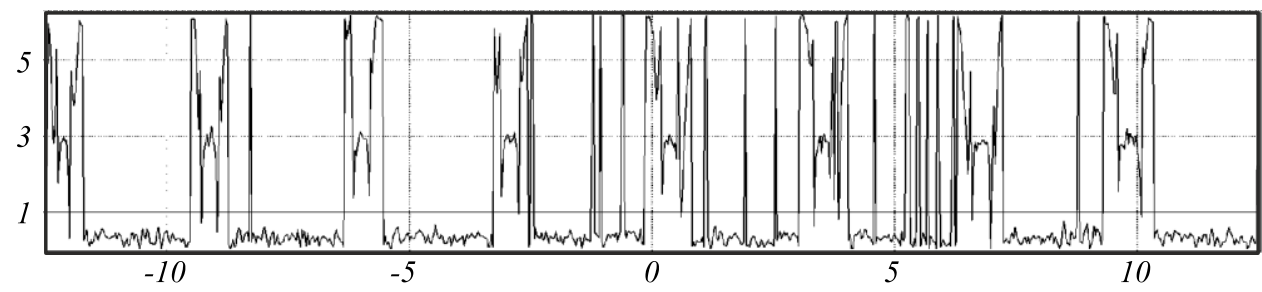

Fig. 5. Section transmissive phase functions obtained from the profilograms in fig. $2 \mathrm{a}$ 
a)
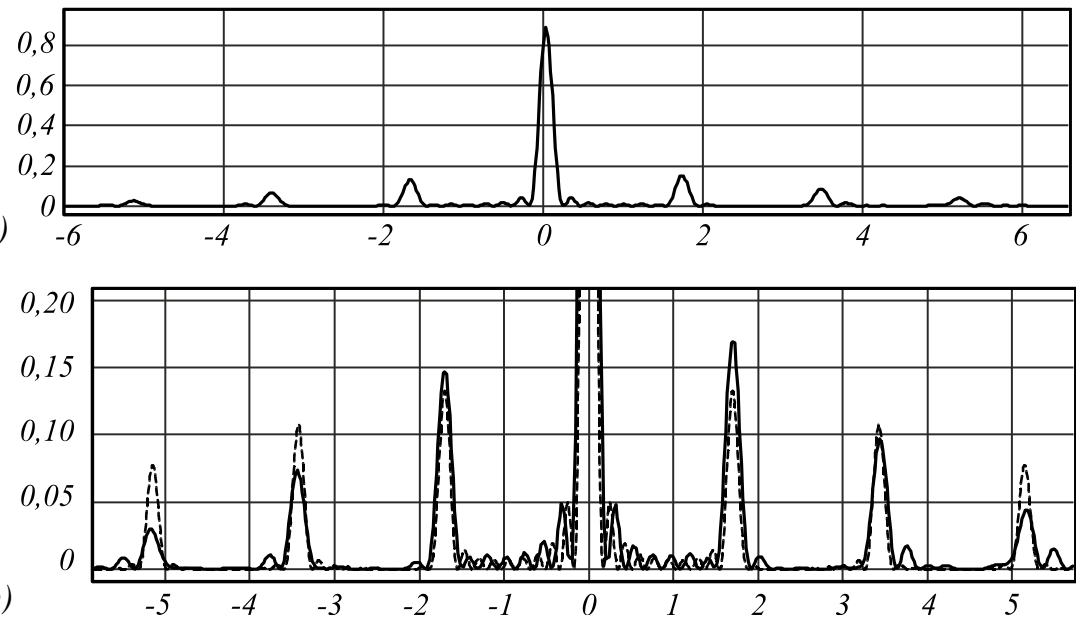

Fig. 6. The intensity distribution orders in the far field diffraction phase structure shown in fig. $5 a)$, the same intensity distribution over orders in the far zone of diffraction from the amplitude structure, shown in fig. 5b) compared to the distribution from a perfect lattice (dashed line) (b)

\section{Conclusion}

The work experimentally shows the possibility of creating optical structures of submicron resolution. Also by simulation it is shown the performance of the generated structures both in amplitude and in phase. The magnitude of the standard deviations for the distributions of intensity of 0.26 and 0.21 , respectively, for amplitude and phase gratings are not critical, assuming the structure of the resulting distributions (there is almost perfect coincidence of the position of diffraction orders). Therefore, demonstrated working technology for forming diffractive structures with a minimum element size of $0.25 \mu \mathrm{m}$.

\section{Acknowledgements}

The work was funded RFBR grants № 14-07-00177, 16-29-09528, 16-29-11744.

\section{References}

1. Zoppel S, Huber H, Reider GA. Selective ablation of thin Mo and TCO films with femtosecond laser pulses for structuring thin film solar cells. Appl Phys, 2007; A89: 161-163.

2. Tan B, Dalili A, Venkatakrishnan K. High repetition rate femtosecond laser nanomachining of thin films. Appl Phys A, 2009; 95: 537-545.

3. Wang XC, Wu LYL, Shao Q, Zheng HY. $355 \mathrm{~nm}$ DPSS UV laser surface texturing on Si substrate. SIMTech technical reports, 2009; 10(4): 203-208.

4. Krause S, Miclea T, Steudel F, Schweizer S, Seifert G. Precise microstructuring of indium-tin oxide thin films on glass by selective femtosecond laser ablation. EPJ Photovoltaics, 2013; 4(40601): 1-5. 
5. Ihlemann J, Schafer D. Fabrication of diffractive phase elements for the UV-range by laser ablation patterning of dielectric layers. Applied Surface Science, 2002; 197-198: 856-861.

6. Heise G., Englmaier M, Hellwig C, Kuznicki T, Sarrach S, Huber HP. Laser ablation of thin molybdenum films on transparent substrates at low fluences. Appl Phys A: Materials Science \& Processing, 2011; 102(1): 173-178.

7. Bauerle D. Laser chemical processing: an overview to the 30th anniversary. Appl Phys A, 2010; 101: 447-459.

8. Alferov SV, Karpeev SV, Khonina SN, Tukmakov KN, Moiseev OYu, Shulyapov SA, Ivanov KA, Savel'ev-Trofimov AB. On the possibility of controlling laser ablation by tightly focused femtosecond radiation. Quantum Electronics, 2014; 44(11): 1061-1065. [in Russian]

9. Zayarny DA, Ionin AA, Kudryashov SI, Makarov SV, Rudenko AA, Bezhanov SG, Uryupin SA, Kanavin AP, Emel'yanov VI, Alferov SV, Khonina SN, Karpeev SV, Kuchmizhak AA, Vitrik OB, and Kulchin YuN. Nanoscale boiling during single-shot femtosecond laser ablation of thin gold films. JETP Letters, 2015; 101(6): 394-397. [in Russian]

10. Volkov AV, Moiseev OY, Poletayev SD. Precision laser recording on a molybdenum films for diffractive microrelief formation. Computer Optics, 2013; 37(2): 220-225. [in Russian]

11. Volkov AV, Moiseev OY, Poletayev SD, Chistyakov IV. Application of thin molybdenum films in contact masks for manufacturing the micro-relief of diffractive optical elements. Computer Optics, 2014; 38(4): 757-762. [in Russian]

12. Volkov AV, Kazanskiy NL, Moiseev OY, Paranin VD, Poletayev SD, Chistyakov IV. Specific Features of the Laser Irradiation of Thin Molybdenum Films. Technical Physics, 2016; 61(4): 579-583. DOI: 10.1134/S1063784216040241.

13. Poleshchuk AG, Churin EG, Koronkevich VP, Korolkov VP, Kharissov AA, Cherkashin VV, Kiryanov VP, Kiryanov AV, Kokarev SA, Verhoglyad AG. Polar coordinate laser pattern generator for fabrication of diffractive optical elements with arbitrary structure. Appl Opt, 1999; 38(8): 1295-1301.

14. Kazanskiy NL. Research \& Education Center of Diffractive Optics. Proceedings of SPIE, 2012; 8410: 84100R. DOI: 10.1117/12.923233.

15. Doskolovich LL, Golub MA, Kazanskiy NL, Khramov AG, Pavelyev VS, Seraphimovich PG, Soifer VA, Volotovskiy SG. Software on diffractive optics and computer generated holograms. Proceedings of SPIE, 1995; 2363: 278-284. DOI: 10.1117/12.199645.

16. Khonina SN, Ustinov AV, Volotovsky SG, Ananin MA. Fast calculation algorithms for diffraction of radially vortical laser fields on the microaperture. Izv. SNC RAS, 2010; 12(4): 15-25. [in Russian]

17. Khonina SN, Ustinov AV, Kovalyov AA, Volotovsky SG. Near-field propagation of vortex beams: models and computation algorithms. Optical Memory and Neural Networks (Information Optics), 2014; 23(2): 50-73.

18. Kazanskiy NL, Kharitonov SI, Doskolovich LL, Pavelyev AV. Modeling the performance of a spaceborne hyperspectrometer based on the Offner scheme. Computer Optics, 2015, 39(1): 70-76. DOI: 10.18287/0134-2452-2015-39-1-70-76. [in Russian]

19. Karpeev SV, Khonina SN, Kharitonov SI. Study of the diffraction grating on the convex surface as a dispersive element. Computer Optics, 2015; 39(2): 211-217. [in Russian] 